\title{
Pancreatic Insulinoma: A Surgical Experience
}

\author{
Mayiluaganan Sabaretnam • Gyan Chand • \\ Anjali Mishra
}

Published online: 30 December 2009

(C) Société Internationale de Chirurgie 2009

We read with interest the article by Espana-Gomez et al. [1] published in the September 2009 issue. This is an interesting article, in which the authors have shared substantial experience of laparoscopic management of pancreatic insulinoma. As is true for all fields of surgery, the minimally invasive approach is making significant headway in the management of pancreatic insulinomas and we congratulate the authors for their contribution [2-4]. However, we have a few comments and queries.

The authors stated that the laparoscopic approach was initially selected for 21 patients. Were these cases randomly selected or did the authors have some selection and/ or exclusion criteria? Considering the fact that the pancreatic fistula rate was the highest in the conversion group (6/7), most of which was consisted of patients with tumor in pancreatic head (5/7), would the authors in the future recommend against attempting laparoscopic approach for patients with tumors in pancreatic head.

According to the authors, calcium stimulation test (ASVS) was performed in nine patients and in four of them the stimulation test confirmed the suspected lesion, whereas in five the results indicated a regional hypersecretion of insulin. Did the authors mean that once a positive gradient was detected in the artery supplying a particular region, a lesion previously detected in the same region by other anatomical imaging modality was definitely considered as being insulinoma or are they referring to occurrence of the arterial blush during the procedure in the 4 of these nine cases? Furthermore, we would like to know the authors' opinion regarding routinely performing the ASVS test in patients planned for the laparoscopic approach. Would this policy make the surgeon feel more confident about finding a lesion during pancreatic exploration and would it result in limited exploration?

\section{References}

1. Espana-Gomez MN, Velázquez-Fernández D, Bezaury $\mathrm{P}$ et al (2009) Pancreatic insulinoma: a surgical experience. World J Surg 33:1966-1970

2. Isla A, Arbuckle JD, Kekis PB et al (2009) Laparoscopic management of insulinomas. Br J Surg 96:185-190

3. Luo Y, Liu R, Hu MG et al (2009) Laparoscopic surgery for pancreatic insulinomas: a single-institution experience of 29 cases. J Gastrointest Surg 13:945-950

4. Toniato A, Meduri F, Foletto M et al (2006) Laparoscopic treatment of benign insulinomas localized in the body and tail of the pancreas: a single-center experience. World J Surg 30:19161918
M. Sabaretnam · G. Chand · A. Mishra $(\bowtie)$

Department of Endocrine Surgery, Sanjay Gandhi Postgraduate

Institute of Medical Sciences, Raebareli Road, Lucknow 226

014, India

e-mail: anjali@sgpgi.ac.in; anjali_mishra2000@yahoo.com 